\title{
Multiple follicle culture supports primary follicle growth through paracrine-acting signals
}

\author{
J E Hornick ${ }^{1,2}$, F E Duncan ${ }^{1,2}$, L D Shea ${ }^{3}$ and T K Woodruff ${ }^{1,2}$ \\ ${ }^{1}$ Department of Obstetrics and Gynecology, Feinberg School of Medicine, Northwestern University, 303 East Superior \\ Street, Lurie 10-250, Chicago, Illinois 60611, USA, ${ }^{2}$ Center for Reproductive Science, Northwestern University, \\ Evanston, Illinois 60208, USA and ${ }^{3}$ McCormick School of Engineering, Northwestern University, Evanston, Illinois \\ 60208, USA
}

Correspondence should be addressed to TK Woodruff at Department of Obstetrics and Gynecology, Feinberg School of Medicine, Northwestern University; Email: tkw@northwestern.edu

J E Hornick and F E Duncan contributed equally to this work

\begin{abstract}
In vitro follicle growth in alginate hydrogels is a unique and versatile method for studying ovarian and follicle biology that may also have implications for fertility preservation. Current culture systems support the development of isolated mouse follicles from the secondary stage onward. However, it has been a challenge to grow smaller follicles in vitro due to the dissociation of the oocyte from companion somatic cells. Recent work has demonstrated that coculturing primary follicles with mouse embryonic fibroblasts or ovarian stromal cells supports follicle survival and growth. In this study, we demonstrate that follicles themselves can exert a beneficial coculture effect. When primary follicles were cultured in groups of five or ten (multiple follicle culture), there was increased growth and survival. The multiple follicle culture approach maintained follicle integrity and resulted in the formation of antral stage follicles containing meiotically competent gametes. The growth and survival of primary follicles were highly number dependent, with the most significant enhancement observed when the largest number of follicles was grown together. Our data suggest that the follicle unit is necessary to produce the secreted factors responsible for the supportive effects of multiple follicle culture, as neither denuded oocytes, oocyte-secreted factors, nor granulosa cells alone were sufficient to support early follicle growth in vitro. Therefore, there may be signaling from both the oocyte and the follicle that enhances growth but requires both components in a feedback mechanism. This work is consistent with current in vivo models for follicle growth and thus advances the movement to recapitulate the ovarian environment in vitro.
\end{abstract}

Reproduction (2013) 145 19-32

\section{Introduction}

In vitro growth of isolated human ovarian follicles is an emerging technology with the aim of expanding the fertility options of young cancer patients (Jeruss \& Woodruff 2009, Xu et al. 2009a, Schmidt et al. 2010). Although the clinical application of in vitro follicle growth (IVFG) is still investigational, in a laboratory setting, it is a robust method to study the basic biology of the ovary and the follicle in a controlled yet modifiable environment. Multiple culture systems have been developed that support the development of isolated mouse preantral follicles from the secondary stage onward (Eppig \& Schroeder 1989, Roy \& Treacy 1993, Spears et al. 1994, Cortvrindt et al. 1996, Eppig \& O'Brien 1996, Abir et al. 1997, 1999, 2001, 2006, Hovatta et al. 1997, Newton et al. 1999, Wright et al. 1999, Gutierrez et al. 2000, Telfer et al. 2000, 2008, Wu et al. 2001, O'brien et al. 2003, Picton et al. 2003, Scott et al. 2004, Kreeger et al. 2006, Xu et al. 2006a,
Thomas et al. 2007, Amorim et al. 2009, West-Farrell et al. 2007a,b, 2009, Romero \& Smitz 2010, Dunning etal. 2011). Each of these culture conditions has its own advantages and provides useful ways to understand follicle function.

We have elected to engineer and use hydrogel-based follicle culture systems in which the oocyte and its companion granulosa cells interact with each other and with the environment reciprocally with the same geometry, connectivity, and dimensionality as they would in the ovary. Alginate-based hydrogels in particular have not only supported the in vitro growth and development of mouse preantral follicles but they also have been translated successfully to several large mammalian species including the domestic dog, baboon, rhesus monkey, and human (Jeruss \& Woodruff 2009, Xu et al. 2009a, 2009b, 2010, 2011, Schmidt et al. 2010, Smitz et al. 2010, Songsasen et al. 2011, Ting et al. 2011). Importantly, follicles cultured in this system have resulted in stage IV oocytes (human), meiosis II 
(MII)-arrested eggs (baboon), and fertilized two-cell embryos (rhesus macaque), and this development has not been achieved in other systems.

Supporting the growth and survival of primordial and primary follicles, however, has been a significant challenge to the field. Typically, isolated primordial and primary follicles degenerate rapidly when cultured due to a loss of critical connections between the oocyte and the granulosa cells (Eppig \& Schroeder 1989, Roy \& Treacy 1993, Spears et al. 1994, Cortvrindt et al. 1996, Eppig \& O'Brien 1996, Abir et al. 1997, 1999, 2001, 2006, Hovatta et al. 1997, Newton et al. 1999, Wright et al. 1999, Gutierrez et al. 2000, Telfer et al. 2000, 2008, Wu et al. 2001, O'brien et al. 2003, Picton et al. 2003, 2008, Scott et al. 2004, Kreeger et al. 2006, Xu et al. 2006a, Thomas et al. 2007, Amorim et al. 2009, West-Farrell et al. 2009, Romero \& Smitz 2010, Dunning et al. 2011, Hornick et al. 2012). Thus, growing these immature follicles in vitro has primarily relied on in situ culture methods (Eppig \& O'Brien 1996, Wandji et al. 1996, 1997, Hovatta et al. 1999, Telfer et al. 2008, jin et al. 2009). The ability to culture isolated follicles, however, has important implications for understanding early follicle development and has clinical relevance for the field of fertility preservation. Accordingly, there is a need to develop culture systems that support these early stages of follicle development.

Early follicle growth is thought to be largely gonadotropin independent and instead under the control of paracrine and autocrine signals from several sources in the ovary, including stromal cells, macrophages, and other follicles (Peters et al. 1975). Several recent studies suggest that these factors also play a central role in vitro in supporting the growth of isolated primary follicles. For example, isolated primary follicles are able to survive and grow when cultured in the presence of purified ovarian stroma composed of theca-interstitial cells and macrophages (Tingen et al. 2011). A similar phenomenon is observed when isolated primary follicles are cultured in the presence of mouse embryonic fibroblasts (MEFs) as a feeder cell layer. Coculture with MEFs results in increased follicle survival, growth, and differentiation (Tagler et al. 2012). Antral follicles derived from this system contain meiotically competent oocytes capable of reaching metaphase II in response to hormone stimulation (Tagler et al. 2012). These studies suggest that individual primary follicles require factors beyond the standard culture media additives, which include insulin, transferrin, selenium, fetuin, $\mathrm{BSA}$, and FSH (Xu et al. 2006a). Although these factors can be supplied in vitro by coculture with stromal cells or MEFs, we hypothesized that follicles themselves may also have a stimulatory effect on IVFG based on in vivo observations.

In the mammalian ovary, there is a distinct architecture and follicle distribution that may influence follicle development. Primordial and primary follicles are found in vivo close to the rigid, collagen-dense ovarian cortex, whereas larger growing follicles are found in the interior medulla, which is less rigid (Woodruff \& Shea 2010, Hornick et al. 2012). In a recent study examining the spatial relationship of follicles within ovaries, it was noted that growing follicles have a stimulatory effect on other follicles (Da Silva-Buttkus et al. 2009). That is, a follicle is more likely to be growing itself if surrounded by other growing follicles. The presumptive morphogen signal is likely to be a secreted paracrine factor based on the range of the stimulatory affect, either an agonist or an antagonist. While primordial follicle activation is likely achieved with paracrine signaling as well, the factors regulating activation may differ from follicle growth. Therefore, we elected to start with primary follicles. We investigated whether culturing primary follicles in groups (multiple follicle culture) was able to enhance their growth, survival, and ability to produce mature gametes. We determined that multiple follicle culture enhanced follicle integrity by means of a diffusible signal from the follicles, thus phenocopying what occurs in vivo.

\section{Results}

\section{Multiple follicle culture improves primary follicle growth and survival in vitro}

To determine whether growing follicles in groups can improve the outcome of IVFG of early preantral follicles, we isolated primary follicles corresponding to type $3 \mathrm{~b}$ and 4 according to the established classification system (Pedersen \& Peters 1968). Morphologically, the type $3 b$ follicles were characterized by a single layer of cuboidal granulosa cells, representing 21-60 granulosa cells in the largest cross section, which we confirmed by immunocytochemistry (Fig. 1A and B). Type $3 \mathrm{~b}$ follicles typically had diameters between 85 and $100 \mu \mathrm{m}$ with an average follicle diameter of $94 \pm 4 \mu \mathrm{m}$ and oocytes with an average diameter of $54 \pm 4 \mu \mathrm{m}$. The type 4 follicles had started to form a second layer of granulosa cells, representing $\sim 61-100$ granulosa cells in the largest cross section (Fig. 1C and D). Type 4 follicles typically had diameters between 100 and $115 \mu \mathrm{m}$ with an average follicle diameter of $107 \pm 4 \mu \mathrm{m}$ and oocytes with an average diameter of $59 \pm 3 \mu \mathrm{m}$. For each of these follicle classes, follicles were grown individually $(x 1)$ or in groups of five $(x 5)$ or ten $(x 10)$ in alginate hydrogels for up to 13 days, and their survival and growth were monitored.

As has been observed previously, although type $3 \mathrm{~b}$ and 4 follicles have already been activated to grow, standard culture in alginate hydrogels does not support their continued development in vitro (Picton et al. 2008). We observed that the survival of individually cultured follicles was only 12.5 and $28.6 \%$ for type $3 b$ and type 4 respectively. However, when these same follicle classes 

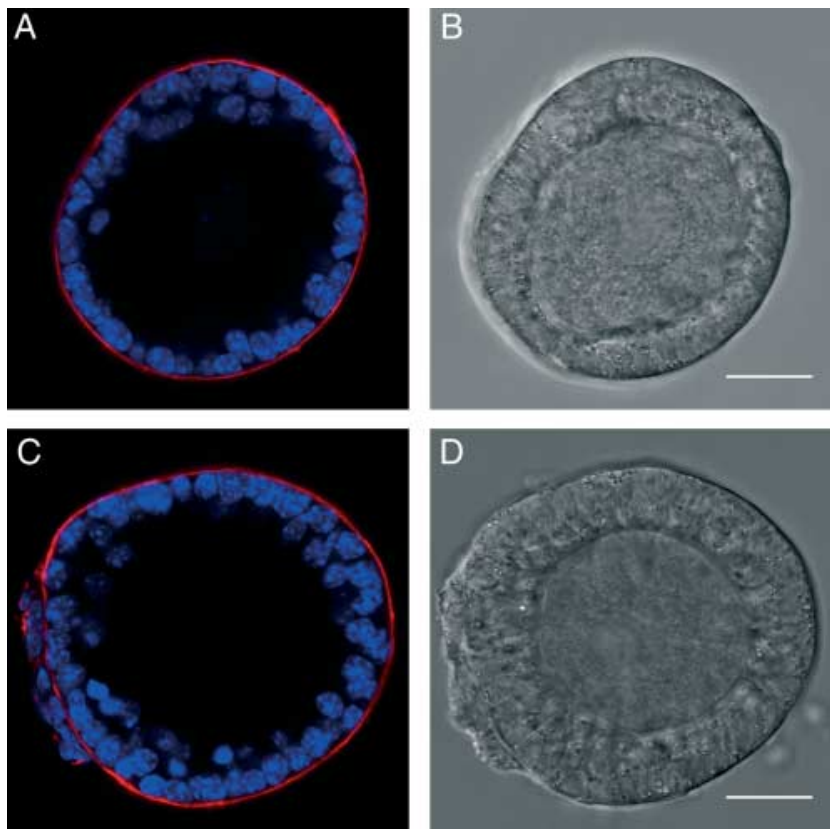

Figure 1 Morphology of small secondary and large primary follicles. A follicle representative of type $3 \mathrm{~b}$ (diameter $85-100 \mu \mathrm{m}$ ) showing a single layer of granulosa cells (A and B). A follicle representative of type 4 (diameter 100-115 $\mu \mathrm{m}$ ) showing a partial second layer of granulosa cells (C and D). Scale bars, $25 \mu \mathrm{m}$.
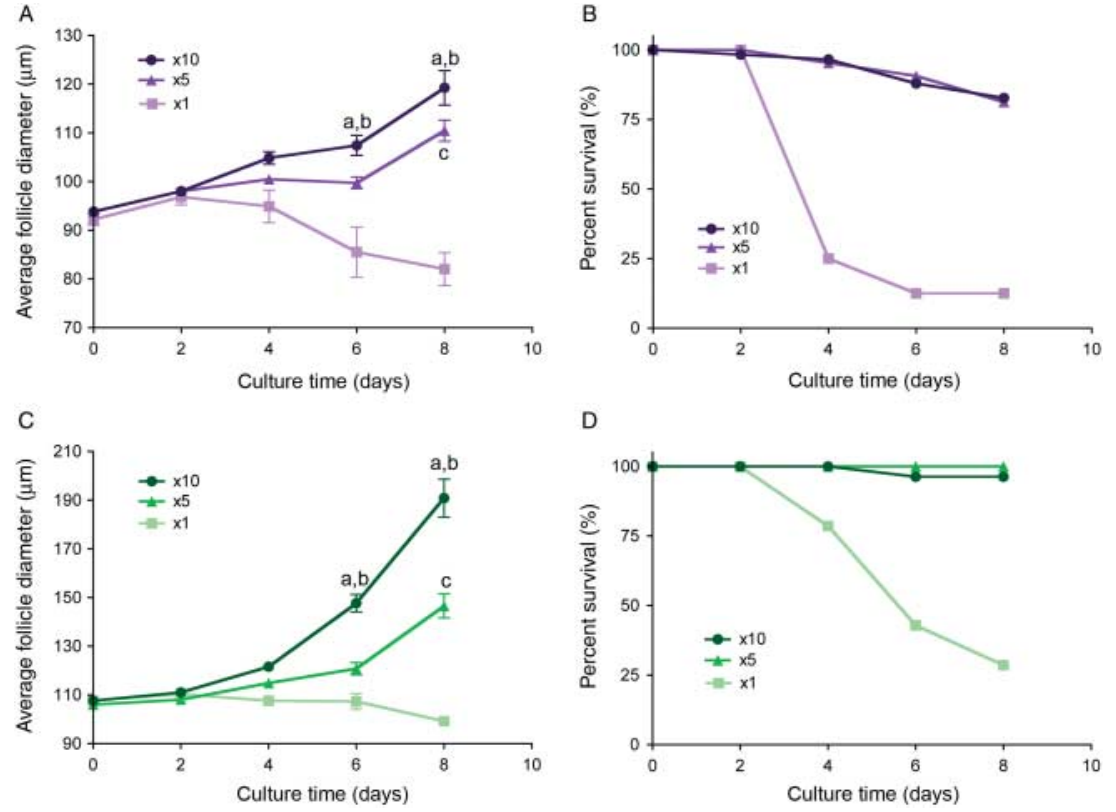

D

were cultured in groups, survival increased significantly (Fig. 2B and D). For example, the survival of the type $3 \mathrm{~b}$ follicles increased to over $80 \%$ in both the $\mathrm{x} 5$ and the $\mathrm{x} 10$ conditions (Fig. 2B). This trend was also reflected in the type 4 follicles where survival was 100 and $96.3 \%$ in the $x 5$ and $x 10$ conditions respectively (Fig. 2D).

In addition to improving follicle survival, multiple follicle culture also promoted follicle growth. When cultured individually, these classes of ovarian follicles did not grow (Figs 2 and $3 \mathrm{~A}$ and $\mathrm{D}$ ). In the type $3 \mathrm{~b}$, the average initial follicle diameter was $92.2 \pm 4.9 \mu \mathrm{m}$, and of those follicles that survived, their diameter on day 8 was $82.0 \pm 4.8 \mu \mathrm{m}$ (Fig. 2A). In the type 4, the initial diameter was $107.7 \pm 5.5 \mu \mathrm{m}$, and on day 8 , it was $99.2 \pm 4.2 \mu \mathrm{m}$ (Fig. 2C). This decrease in average diameter was due to granulosa cell death (pyknotic, dark) and/or decrease in oocyte diameter due to poor oocyte health (dark, shriveled). In contrast, follicles cultured in groups of $x 5$ or $x 10$ showed improved growth over those cultured individually (Figs 2, 3 and 4). Type $3 \mathrm{~b}$ follicles in the $x 5$ culture grew to an average diameter of $110.5 \pm 15.7 \mu \mathrm{m}$ by day 8 , an average increase of $16.7 \mu \mathrm{m}$ (Fig. 2A). Type $3 \mathrm{~b}$ follicles in the $\mathrm{x} 10$ culture grew to an average diameter of $119.3 \pm 24.6 \mu \mathrm{m}$, an average increase of $25.5 \mu \mathrm{m}$ (Fig. 2A). Type 4 follicles in the $x 5$ culture grew to an average diameter of 146.6 $\pm 32.8 \mu \mathrm{m}$ at day 8 , an average increase of $40.6 \mu \mathrm{m}$

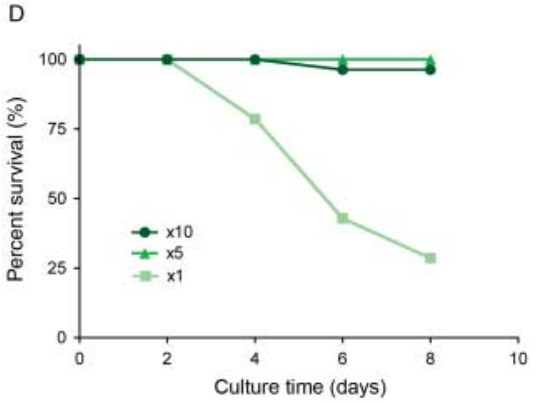

Figure 2 Multiple follicle culture is necessary for late primary and early secondary follicles to survive and grow in vitro. Follicles grown in groups reach statistically larger terminal diameters than those cultured individually (A and C). For type 3b follicles, starting diameter $85-100 \mu \mathrm{m}$ (A), differences in growth achieve significance by day 6 of culture in the $x 10$ group (a: $x 5$ vs $x 10, P<0.01 ;$ b: $x 1$ vs $x 10, P<0.001$ ) and day 8 of culture in the $x 5$ group (c: $x 1$ vs $x 5, P<0.01$ ). Type 4 follicles, starting diameter 100-115 $\mu \mathrm{m}(\mathrm{C})$, also see significant difference in growth by day 6 of culture in the $x 10$ group (a: $x 5$ vs x10, $P<0.001 ;$ b: $x 1$ vs x10, $P<0.001$ ) and day 8 of culture in the $x 5$ group (c: $x 1$ vs $x 5, P<0.001$ ). Follicles encapsulated and grown in groups have increased survival during culture compared with those cultured individually (B and D). Follicle survival is also dependent on the initial follicle diameter. Data is reported for the first 8 days of culture when measurements are the most accurate. Data are from two independent experiments and more than 45 follicles were analyzed for each group. 

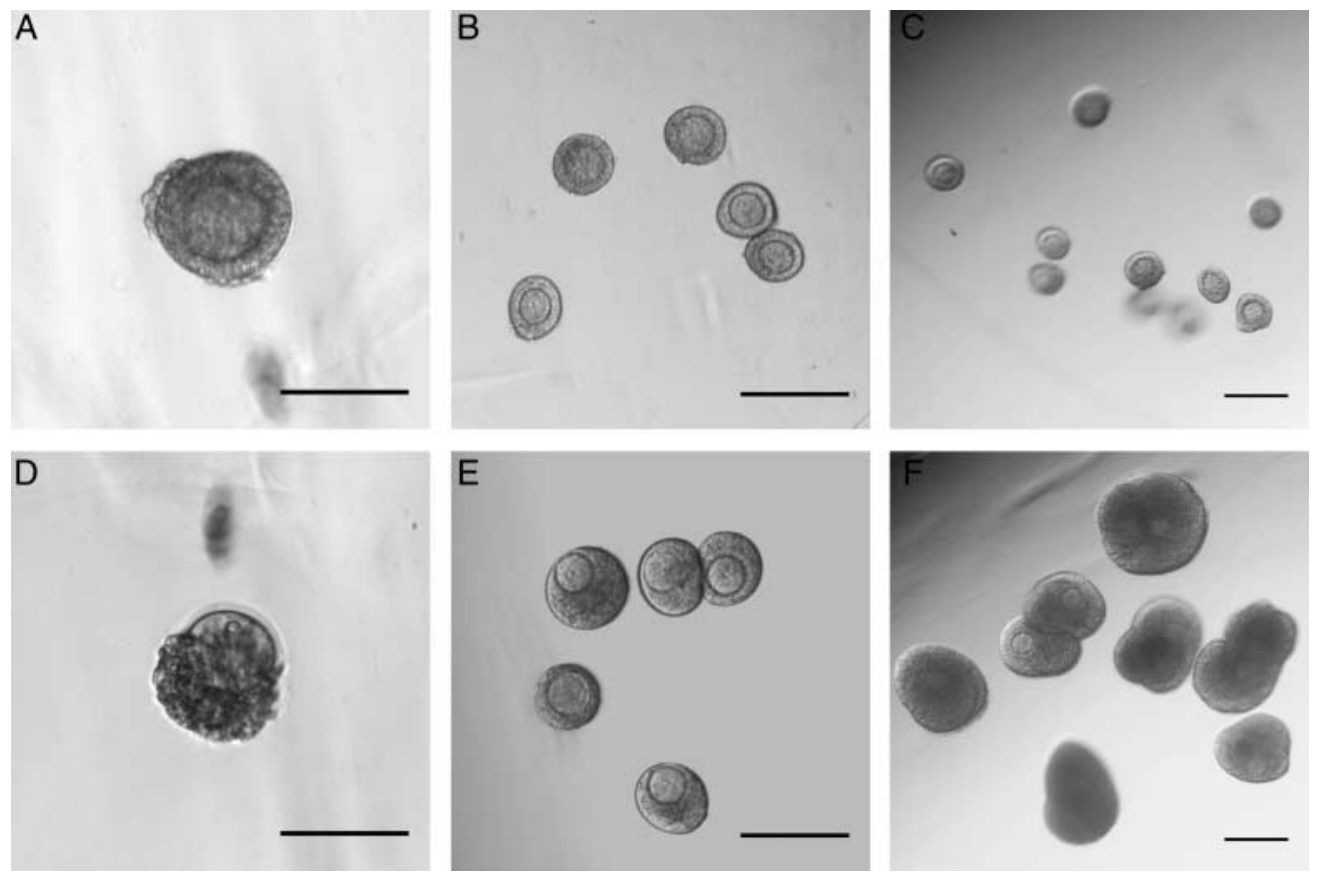

Figure 3 Multiple follicle culture enhances growth and survival in a number-dependent manner. Representative images of beads containing one, five, and ten follicles at day 0 (A, B and C) and day 8 (D, E and F). A large fraction of follicles (starting size 85-115 $\mu \mathrm{m}$ in diameter) encapsulated individually lose integrity by 8 days of culture as evidenced by the oocyte having dissociated from the granulosa cells (A and D). In contrast, follicles encapsulated in groups of five (B and E) or ten (C and F) maintain their integrity and grow significantly. Scale bars, $200 \mu \mathrm{m} .{ }^{*}$ specific follicle magnified.

(Fig. 2C). Type 4 follicles in the $\mathrm{x} 10$ culture grew to an average diameter of $190.9 \pm 51.6 \mu \mathrm{m}$ at day 8 , an average increase of $83.2 \mu \mathrm{m}$ (Fig. 2C). Follicle growth in the $\mathrm{x} 10$ condition was significantly greater by day 6 of culture compared with the growth in the $\mathrm{x} 5$ or individual conditions for both follicle classes (Fig. 2A and C). Overall, multiple follicle culture promoted increased growth and survival of late primary and early secondary follicles.

\section{Multiple follicle culture supports the production of oocytes that are meiotically competent}

To determine whether those follicles that survived and grew following multiple follicle culture were capable of producing meiotically competent oocytes, we performed in vitro maturation of follicles grown in the $x 10$ conditions. We found that follicles from both classes produced oocytes capable of reaching MII following hormonal stimulation as evidenced by extrusion of the first polar body (Fig. 5). Of the type $3 \mathrm{~b}$ follicles, $41 \%$ of oocytes from in vitro cultured follicles matured to MII compared with $57 \%$ of early secondary follicles (Fig. 5B). This maturation rate is lower than previously reported for multilayer secondary follicles but consistent with that reported for primary follicles (Xu et al. 2006b, Tagler et al. 2012). These data suggest that multiple follicle culture is sufficient to stimulate the growth of isolated primary follicles to the point that they can produce a mature gamete.

\section{Multiple follicle culture rescues loss of follicle integrity in in vitro culture}

To determine the mechanism by which multiple follicle culture enhances primary follicle growth and development in vitro, we performed a more detailed analysis of follicle integrity, or the morphological structure of the oocyte relative to the surrounding somatic cells. As was described earlier, primary follicles grown individually exhibited low survival in culture (Fig. 2). This low survival was most often due to an early loss of follicle integrity visualized by an oocyte that was no longer surrounded by granulosa cells (Figs 3D and $4 \mathrm{~A}$, day 6). Once denuded, the oocytes often became dark and/or shriveled and did not survive longterm culture. For type $3 \mathrm{~b}$ and type 4 follicles cultured individually, the extrusion of the oocyte from the follicle occurred in 87.5 and $71.4 \%$ of the cases respectively (Fig. 6A). However, the multiple follicle culture was able to partially prevent loss of follicle integrity and oocyte extrusion (Fig. 6A and C). In the type $3 \mathrm{~b}$ follicles, multiple follicle culture reduced loss of follicle integrity to only 20.3 and $29.3 \%$ in the $x 5$ and $x 10$ culture conditions respectively. In the type 4 follicles, this improvement was even more robust with the oocyte extrusion phenotype occurring in 12.8 and $1.9 \%$ of the cases in the $\times 5$ and $\times 10$ cultures respectively (Fig. 6A).

Although follicle integrity was significantly improved with multiple follicle culture, there was still a fraction of 
Day 0
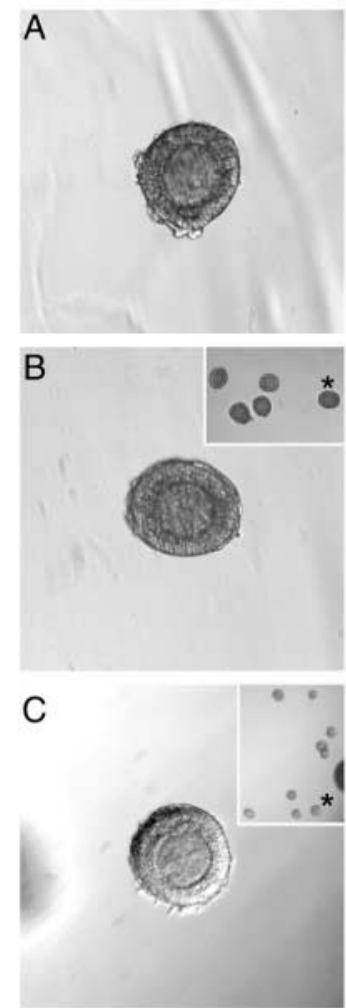

Day 2
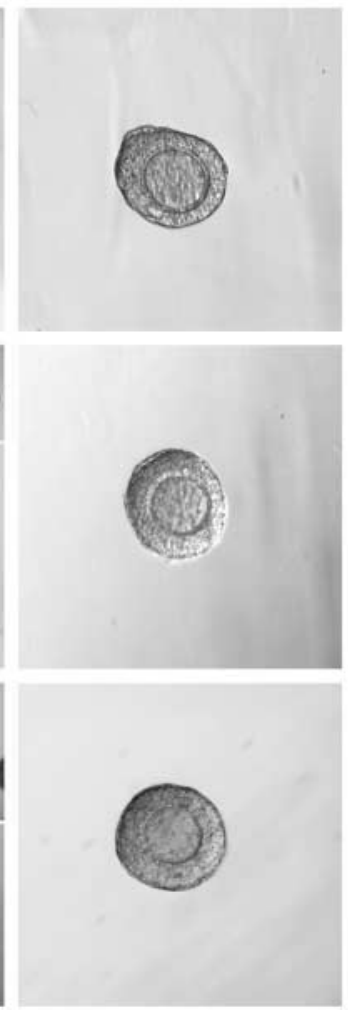

Day 4
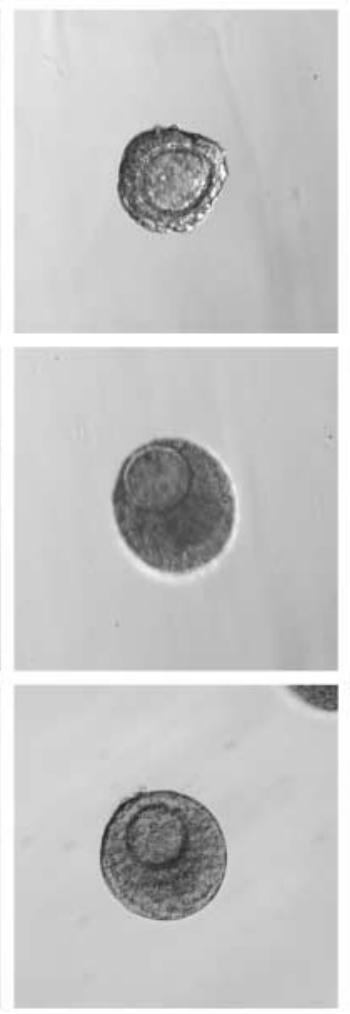

Day 6
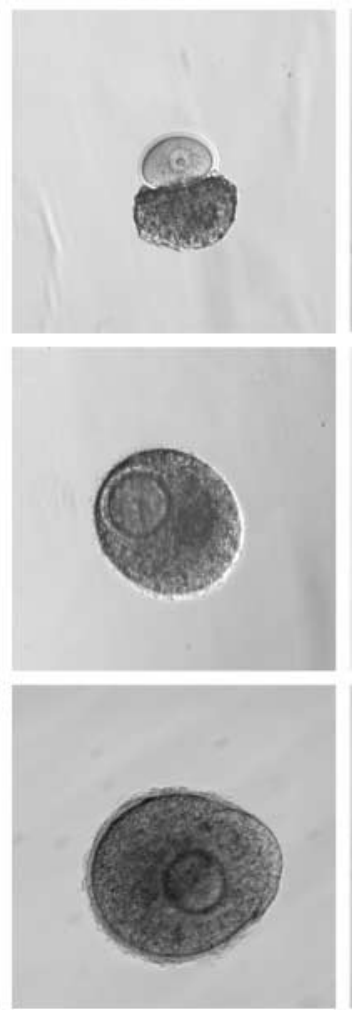

Day 8
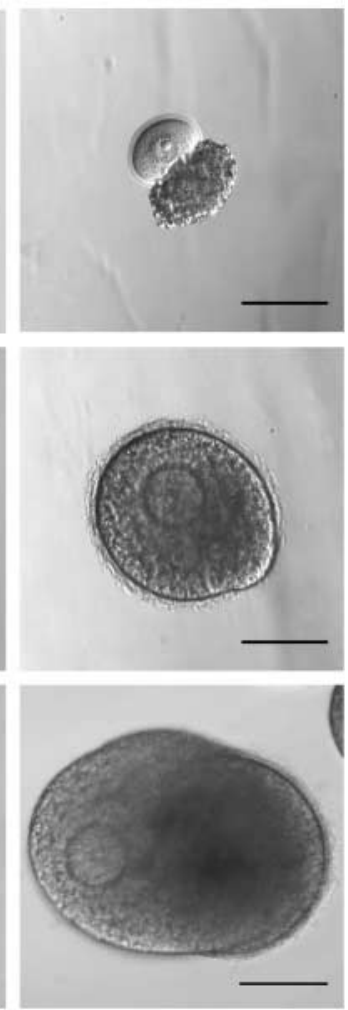

Figure 4 Encapsulated follicles tracked throughout culture. Follicles cultured individually (A), in groups of five (B, inset-whole bead), or groups of ten $(C$, inset-whole bead) were tracked over culture period. Follicles grown in groups show improved growth and survival (B and $C)$ when compared with individually (A). Follicles in x10 group form antrum by day 8 of culture (C, day 8$)$. Scale bars, $100 \mu$ m.

these follicles that exhibited extrusion of the oocyte from the follicle. Interestingly, however, the majority of these follicles cultured in the $x 5$ and $\times 10$ culture conditions were actually able to reform a normal follicular structure shortly after oocyte extrusion (Fig. 6B). In the $x 5$ and $x 10$ cultures, 53.8 and $76.5 \%$ of the type $3 \mathrm{~b}$ follicles that had an extruded oocyte were able to reform normal follicle structure respectively. In the type 4 follicle class, $100 \%$ of the follicles that had an extruded oocyte were able to reform (Fig. 6B). Reformed follicles had two distinctive features. First, when the oocyte was partially extruded, it never turned dark or shriveled (Fig. 6C, day 6, arrow). Secondly, the granulosa cells began growing around the oocyte again (Fig. 6C, day 8) until a complete follicle was reformed. Before reformation, there was no evidence of uncontrolled granulosa cell growth and the oocytes were healthy, characterized by uniform cytoplasm, an intact germinal vesicle (GV), and a zona pellucida. Of note, such reformation was never observed in individual follicle culture where the connections between the oocyte and the granulosa cells were irreversibly lost (Fig. 6B). The reformed follicular structure is likely to have been formed by a combination of reorganization as well as an increase in proliferation of the remaining granulosa cells. These data indicate that the multiple follicle culture improves follicle integrity by both decreasing the chances of oocyte extrusion and also increasing the rate of follicle reformation.

\section{Rescue of follicle integrity is associated with increase in transzonal projections}

To understand the cellular basis by which multiple follicle culture improves follicle integrity, we examined the physical connections, or transzonal projections (TZPs), between the oocyte and the granulosa cells. TZPs are cytoskeleton-enriched structures that emanate from the granulosa cells and extend through the zona pellucida into the oocyte (Anderson \& Albertini 1976). Previous work has demonstrated that the oocyte and surrounding granulosa cells communicate through Cx37-mediated gap junctions formed at the base of the TZPs (Anderson \& Albertini 1976, Carabatsos et al. 1998, Kidder \& Mhawi 2002, Barrett et al. 2010). TZPs are first observed in vivo in primary follicles and are essential for continued follicle development and oocyte health (Carabatsos et al. 2000). In this study, we assessed the number of actin-based TZPs in follicles grown individually or in the $\mathrm{x} 10$ condition by line scan analysis at day 2 of culture (Fig. 7). Day 2 was selected because there are not appreciable differences in growth 
characteristics between the two groups at this time point, and it immediately precedes the time when high levels of oocyte extrusion are observed. Thus, we reasoned that day 2 measurements may be predictive of future loss of follicle integrity. In fact, we observed that follicles cultured individually had significantly fewer TZPs than those cultured in the $x 10$ conditions (Fig. 7). This difference was quantified by line scan analysis which showed that follicles cultured individually had an average of $4.2 \pm 1.0 \mathrm{TZPs} / 10 \mu \mathrm{m}$, whereas those cultured in groups of ten had $8.1 \pm 1.4 \mathrm{TZPs} / 10 \mu \mathrm{m}$ (Fig. 7C, $P<0.05)$. The number of TZPs between follicles grown under $x 1$ and $x 10$ conditions were not due to differences in oocyte growth, as the oocyte diameter was similar between the two groups (Fig. 7D). Additionally, the difference in the number of TZPs cannot be attributed to differences in granulosa cell number, as there was no significant difference in granulosa cells (Fig. 7E). These

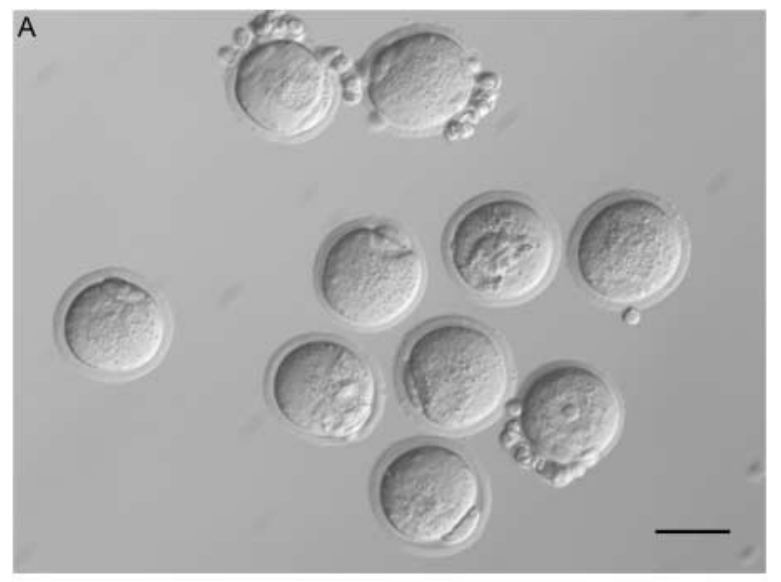

B

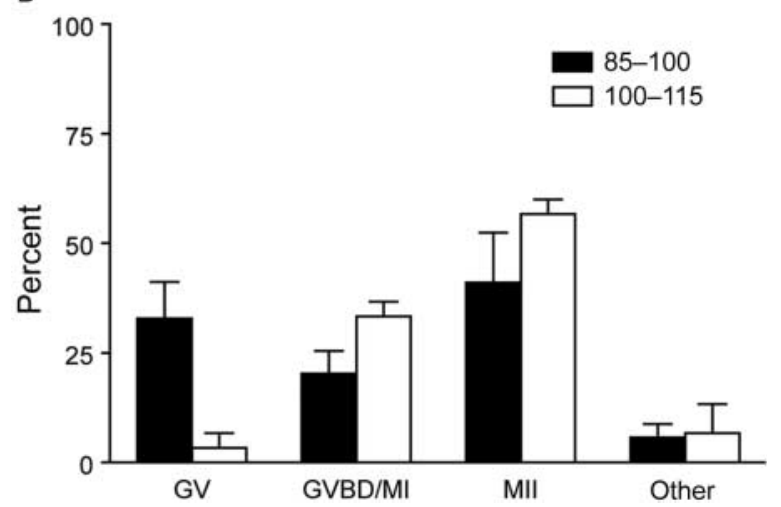

Figure 5 Multiple follicle culture allows small preantral follicles to produce maturation-competent oocytes. Representative image of a pool of oocytes after in vitro maturation, showing mature eggs arrested at meiosis II (MII) with an extruded polar body and oocytes that remain germinal vesicle intact (A). Oocytes from follicle-follicle coculture resume meiosis and arrest at MII at a rate 41 and $57 \%$ from the smaller and larger cohort respectively (B). There was no significant difference between the maturation rate of the two groups. Data are from two independent experiments and more than 30 oocytes were analyzed from each group. data demonstrate that there are more connections between the oocyte and the granulosa cell when follicles are cultured in the presence of other follicles.

\section{Multiple follicle culture rescues follicle survival by secreted factors}

Multiple follicle culture may improve follicle outcomes through paracrine signaling from one follicle to another. In secondary and later stage follicles, oocytes regulate the growth and differentiation of the granulosa cells through soluble, secreted growth factors (reviewed in Gilchrist et al. (2004)). Previous work has shown that isolated oocytes or oocyte-secreted factors (OSFs), including GDF9, BMP15, and FGF8, can regulate the function of mural granulosa and cumulus cells (Gilchrist et al. 2001, 2003, 2004, 2006, Sugiura et al. 2007). Moreover, it has been suggested that the oocyte orchestrates the rate of follicle development (Su et al. 2009). To determine whether oocyte-specific factors were responsible for the observed enhancement of follicle development during multiple follicle culture, two approaches were taken. First, individual follicles were cultured in the continuous presence of denuded oocytes (Fig. 8A), and secondly, they were cultured in the presence of a previously characterized cocktail of OSFs (Sugiura et al. 2007). In these experiments, we did not observe a difference in the growth and survival of follicles cultured in the presence of denuded oocytes or OSFs when compared with individual follicles cultured alone (Fig. 8B). Conversely, previous work has demonstrated that somatic cells alone can support small follicle growth (Tingen et al. 2011, Tagler et al. 2012). However, the somatic cells used in those studies were mixed populations of ovarian cells, not granulosa cells. To test whether granulosa cells alone, but in the context of the follicle rather than dissociated and plated, can support the growth of primary follicles, we devised a system of removing the oocyte from primary follicles while leaving the granulosa cells intact using the XYClone laser system (termed laser-assisted oocytectomy, LAX). The laser is a $300 \mathrm{~mW}$ infrared solid-state diode laser attached to a microscope objective that allows for targeted delivery of a laser pulse to a precise location on a sample. The specific damage to the oocyte was confirmed using a live/dead assay. Control follicles were largely positive for calcein AM with a small number of granulosa cells positive for ethidium homodimer, indicating cell death (Fig. 9A). LAX follicles were also largely positive for calcein AM; however, the oocyte was strongly positive for ethidium homodimer, indicating that the oocyte was dead (Fig. 9B). To assay whether granulosa cells alone, in the form of LAX follicles, can support the growth and survival of primary follicles, LAX follicles were encapsulated in alginate hydrogel in groups of ten and cultured in the presence of an individually encapsulated primary follicle (LAX coculture). However, LAX coculture follicles grew at the 


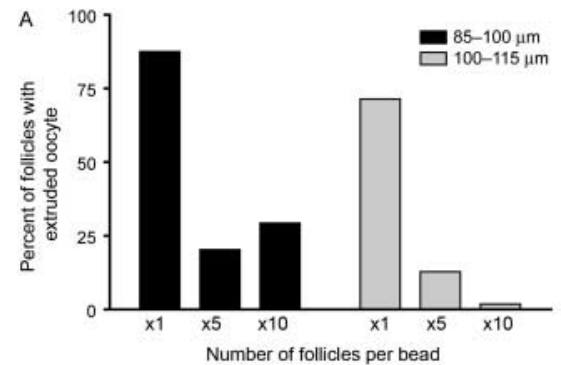

C

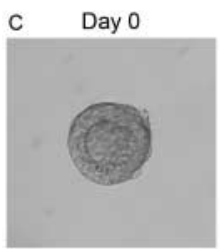

Day 2
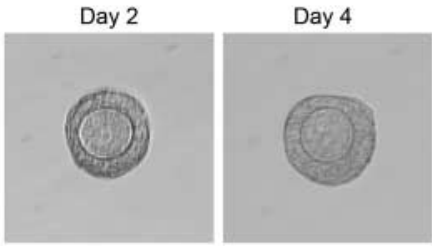

same rate as control primary follicles and had comparable rates of oocyte extrusion (Fig. 9E and data not shown). Additionally, survival between the groups was comparable, with 47 and $50 \%$ for the LAX coculture and control respectively. We verified that the LAX follicles were still alive after the culture period by repeating the live/dead assay. At day 8 , control follicles are primarily positive for calcein AM and have a normal follicular structure with an oocyte surrounded by granulosa cells (Fig. 9C). The LAX follicles were also positive for calcein AM, indicating that the granulosa cells were indeed still alive but lacked any evidence of an oocyte (Fig. 9D). These data suggest that granulosa cells alone cannot support primary follicle growth in the same manner as the group follicle culture.
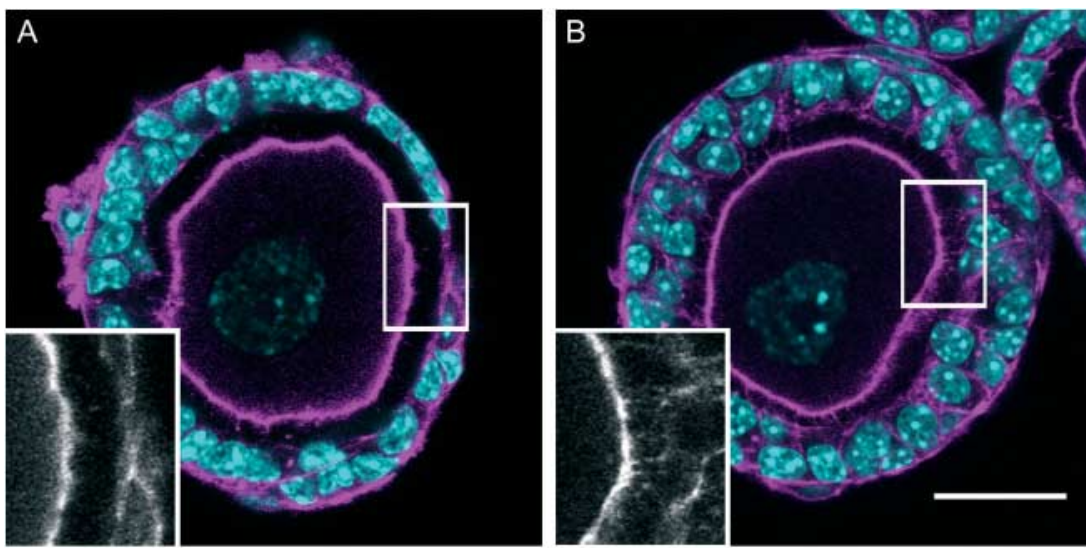

C

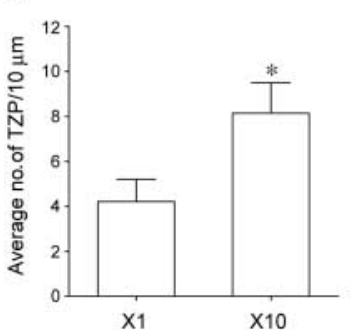

D

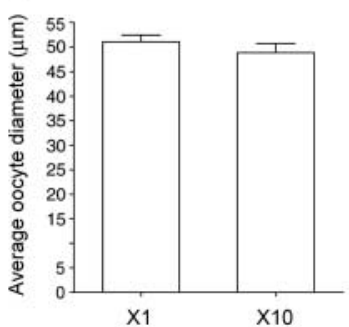

E

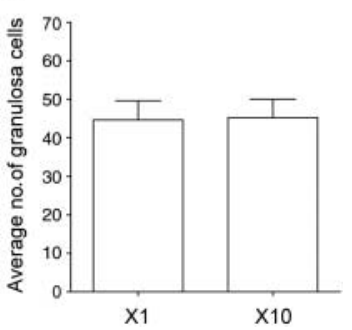

Figure 6 Multiple follicle culture rescues loss of follicle integrity. Primary follicles cultured individually demonstrate characteristic oocyte pop-out phenotype. Follicles cultured in groups of five or ten have oocyte pop-out less frequently than when cultured individually (A). Follicles that have oocyte pop-out reform when they are cultured in groups of five or ten (B). Representative image of reformation phenotype $(\mathrm{C})$. Oocyte begins to extrude from granulosa cells (C, arrow) but then reforms a follicular structure with further culture (C, day 8).
To instead determine whether the necessary factors that promote growth and survival of the primary follicles were intrinsic to intact follicles, we cultured encapsulated individual follicles in the same well as a bead containing ten follicles ( $x 1+x 10$, Fig. 10), mimicking the LAX cultures. In this manner, we can demonstrate that the supportive growth effect seen in the group culture is indeed due to secreted, paracrine factors from the intact follicles, rather than a single follicle cell type or general growth factors produced by adjacent cells. In fact, we observed that individual follicles could survive and grow to the antral stage when cultured adjacent to a bead containing ten follicles, recapitulating the phenotype seen in follicles grown in groups (Fig. 10). Compared
Figure 7 Transzonal projections (TZPs) are significantly increased in follicles cultured in groups. On day 2 of culture, follicles grown in groups had significantly more TZPs compared with those grown individually (A, B and C). TZPs were detected by immunocytochemistry for actin ( $A$ and $B$, insets) and quantified by line scan analysis of confocal sections $(C, * P<0.03)$. No differences were observed in oocyte diameter (D) or in number of granulosa cells (E). Oocyte diameter measurements and granulosa cell counts were done in same optical sections as those used for line scan analysis. Data are from two independent experiments. Representative images are shown. Scale bar, $25 \mu \mathrm{m}$. 

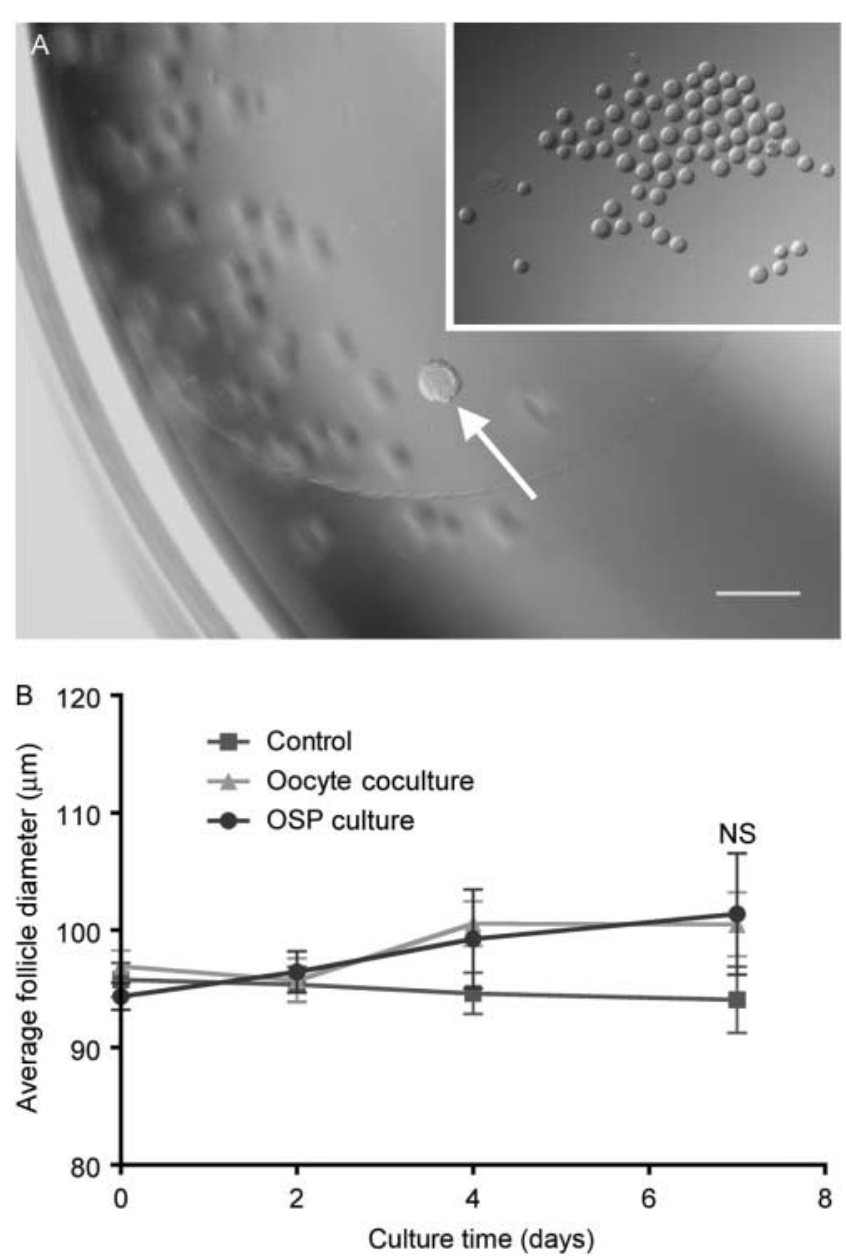

Figure 8 Oocytes alone or oocyte-secreted factors (OSFs) do not rescue primary follicles in culture. Representative image of follicle (arrow) in alginate hydrogel bead in culture well with denuded oocytes (A, inset). A primary follicle grown in the presence of denuded oocytes or supplemented with OSFs does not grow significantly larger than control follicles (B). Data are from two independent experiments and more than 25 follicles were analyzed from each group. NS, not significant.

with follicles grown individually, those follicles grown in the $x 1+x 10$ condition reached significantly larger terminal diameters by day 10 (Fig. 10A). Interestingly, the supportive growth effect was delayed in the $x 1+x 10$ culture compared with the $\times 10$ culture, with growth becoming significantly different on day 10 vs day 6 respectively (Figs $3 \mathrm{C}$ and $10 \mathrm{~A}$ ). These data taken together suggest that there is a secreted factor from growing follicles that supports the development of other growing follicles.

\section{Discussion}

In this study, we demonstrate that isolated primary ovarian follicles can survive and grow when cultured in the presence of other follicles in a size- and numberdependent manner (Fig. 11). We show that follicles grown in groups have more TZPs than those grown individually. This increase in cellular connections is likely the mechanism preventing the dissociation of the oocyte and granulosa cells, a phenotype commonly observed when primary follicles are grown individually in vitro. Follicles grown together secrete a factor or combination of factors that, through paracrine signaling, promote the growth and survival of neighboring follicles. These factors are derived from the intact follicles themselves as follicle integrity was not maintained by coculture with denuded oocytes alone or OSFs. Because the multiple follicle culture approach maintains follicle
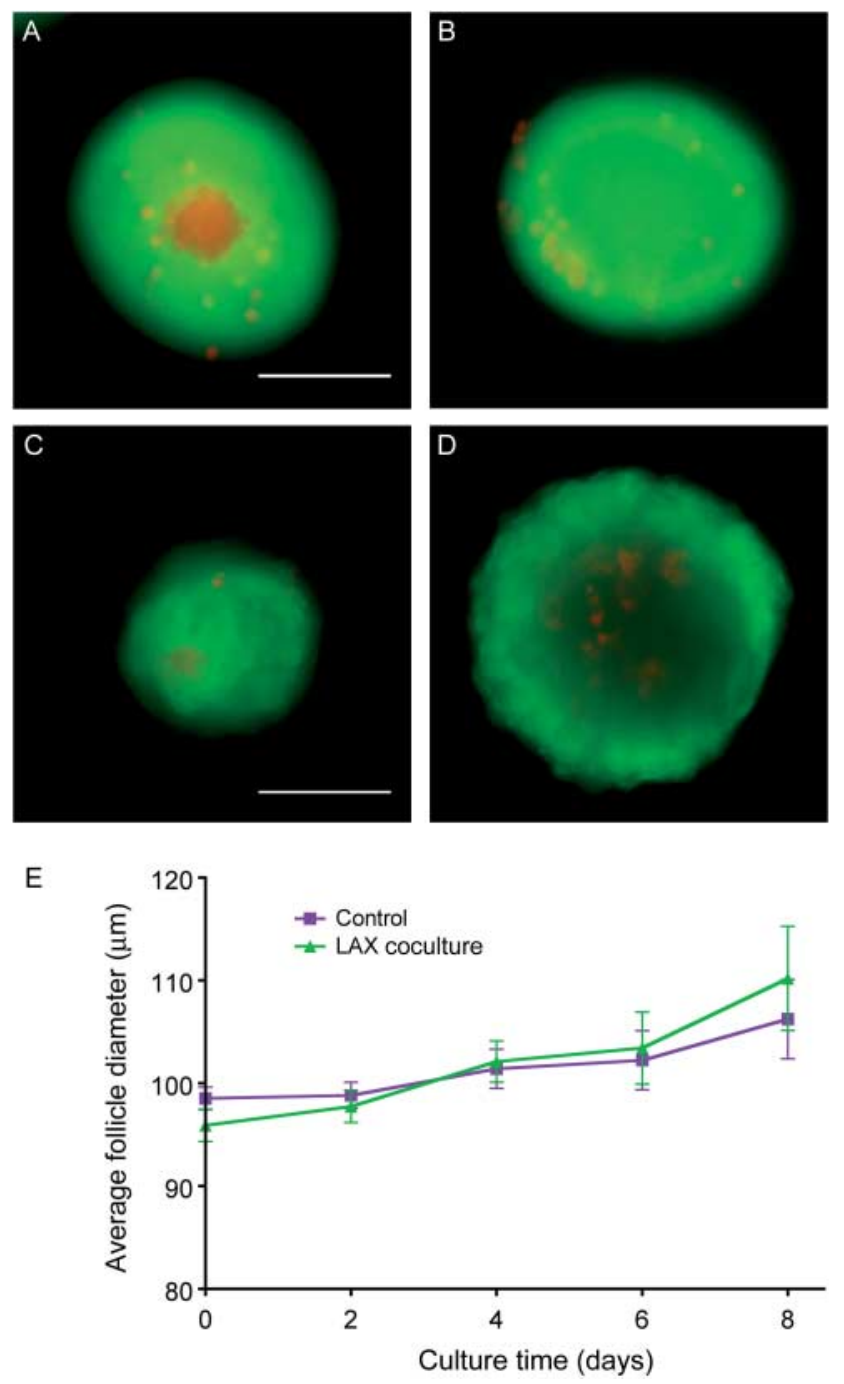

Figure 9 Granulosa cells alone do not support primary follicles in culture. The oocytes were removed from primary follicles by laserassisted oocytectomy (LAX) in order to create granulosa cells without an oocyte in the context of a follicle. Representative follicle showing the specific damage to the oocyte (A), compared with a control follicle (B). After 8 days of culture, the viability of the LAX follicles and the lack of an oocyte can be seen (C), compared with a control follicle after 8 days of culture (D). A primary follicle cultured in the same well as ten LAX follicles (X10 LAX $+\mathrm{x} 1)$ grows at the same rate as an individual primary follicle $(\mathrm{x} 1, \mathrm{E})$. Data are from two independent experiments and more than 35 follicles were analyzed from each group. Scale bar, $100 \mu \mathrm{m}$. 
A
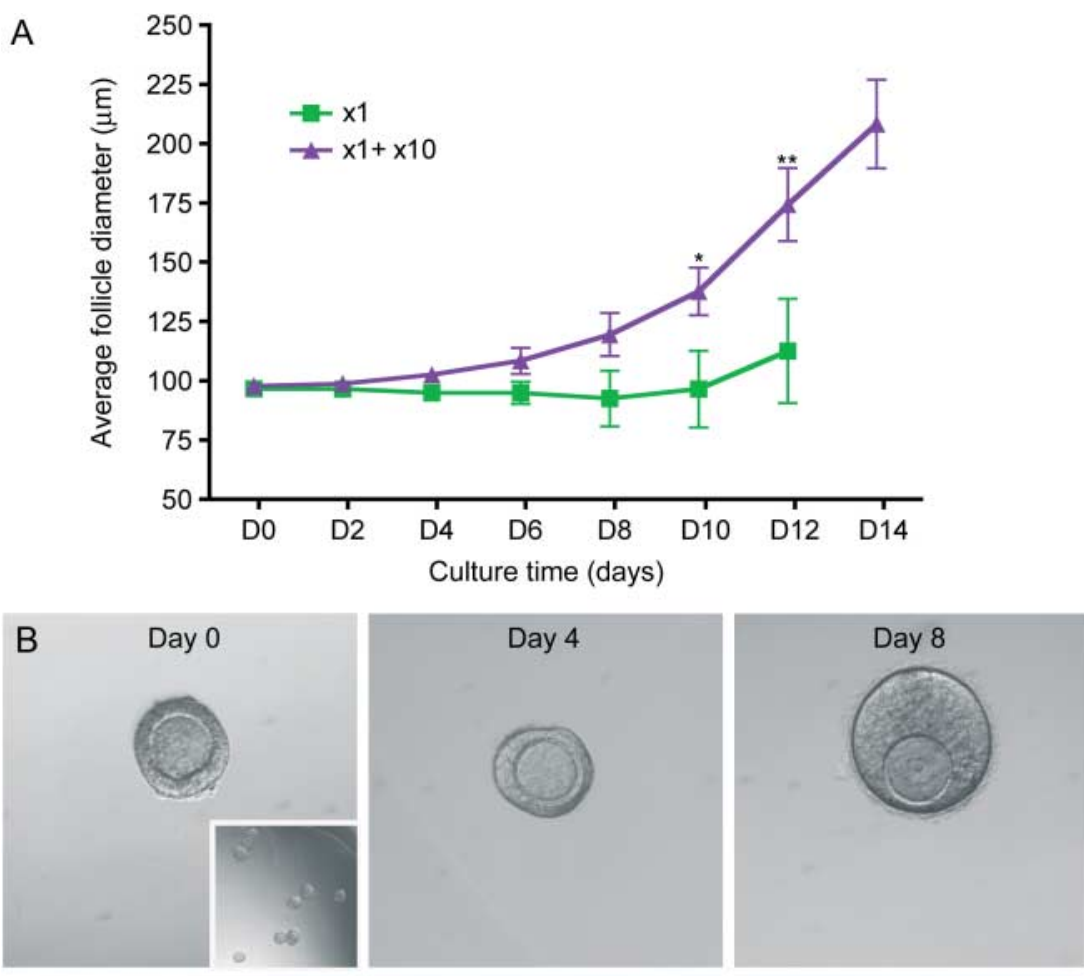

Day 10
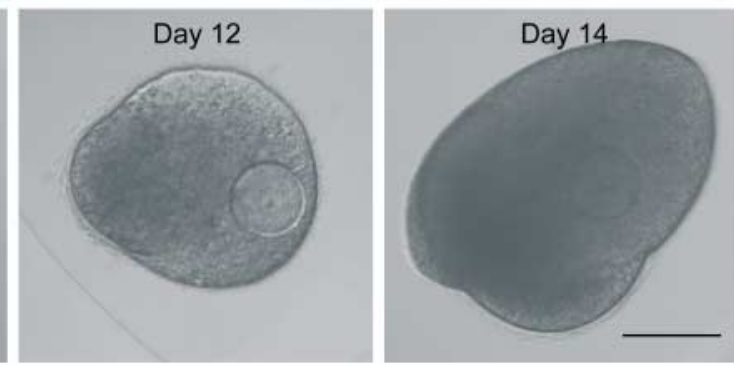

Figure 10 Follicles in alginate secrete a diffusible, supportive signal that promotes follicle growth. A follicle grown adjacent to a bead containing ten follicles $(x 1+x 10)$ grows significantly larger than a follicle grown individually ( $\mathrm{A},{ }^{*} P<0.05$, $\left.{ }^{* *} P<0.001\right)$. Measurements shown are only from the individual follicles and not the follicles in the $\mathrm{x} 10$ alginate bead. Data are from two independent experiments and more than 25 follicles were analyzed from each group. Representative individual follicle with $\mathrm{x} 10$ bead (B, day 0 and inset) grown at day 14 (B). Scale bar, $100 \mu \mathrm{m}$. integrity and promotes follicle growth and development, we were able to obtain antral stage follicles beginning from the late primary stage. These antral follicles are capable of producing meiotically competent gametes.

These results present a significant advantage over recent advances in the improvement of IVFG for the earliest stages of follicle development. Compared with coculture of primary follicles with MEFs, the multiple follicle culture system is free from introduction of a foreign cell type. Additionally, it improves upon coculture with ovarian thecal-interstitial cells because there is minimal processing of ovarian tissue beyond isolation of the follicles, it is more physiologically relevant than dissociated ovarian cells, and it is a more well-defined population of cells. Moreover, when translating IVFG to the clinical setting of fertility preservation, follicles will need to be isolated from slow frozen or vitrified-thawed ovarian tissue. In such situations, the stroma may not be suitable for further processing.

In the mouse ovary, it appears that growing follicles may produce a signal that stimulates local growth of other follicles (Da Silva-Buttkus et al. 2009). In the predictive model proposed by Da Silva-Buttkus et al., the likelihood that a follicle was growing was increased relative to the number of growing follicles in the vicinity. In our multiple follicle culture system, the growth and survival of late primary and early secondary follicles were highly dependent on the number of follicles cultured together with the most significant enhancement observed with the highest number of follicles. These results imply that mechanisms governing follicle growth and development in vivo are also conserved in vitro. We thus have developed a robust model system to isolate the molecular nature of the signal. Current studies are focused on elucidating the factor or factors responsible for promoting growth and survival of neighboring follicles by determining the metabolic, lipid, and protein profiles of the media secreted in the multiple follicle culture system. Interestingly, although the follicle density in the human ovary is much less than in the mouse, we have observed that growing follicles tend to be found in clusters in the human ovarian cortex (our unpublished 


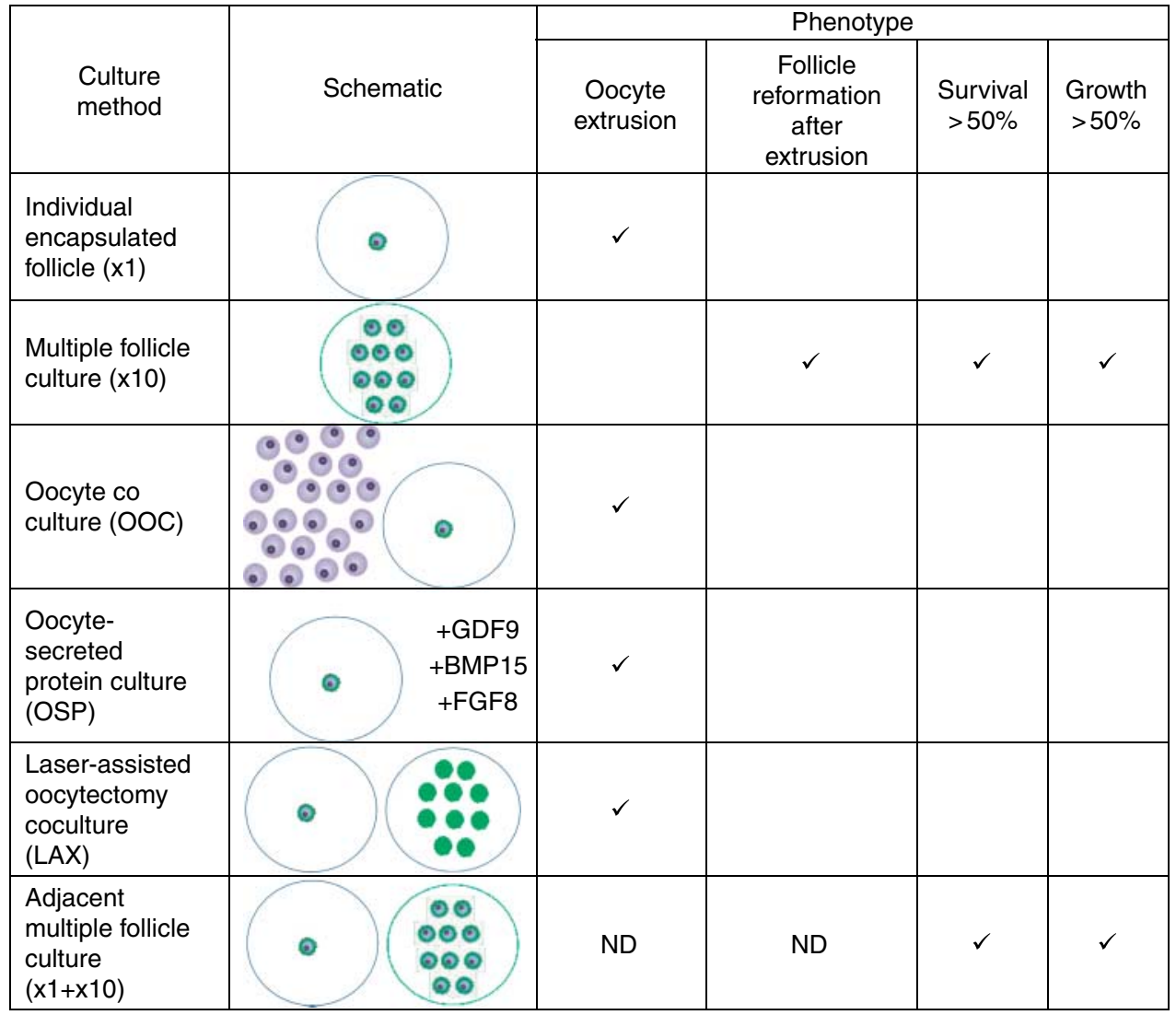

Figure 11 Summary of results. The outcomes of the various culture methods, described pictorially with a corresponding schematic, are tabulated. If the phenotype was present in a significant portion of the follicles, it was considered to be representative of the culture method. ND, not determined.

observations). This suggests that a similar phenomenon may also occur in humans. However, humans are mono-ovulatory, in contrast to mice, which are polyovulatory, so potentially only the early stages of follicle development in the human will benefit from multiple follicle culture.

A main benefit of multiple follicle culture appears to be the maintenance of follicle integrity during IVFG. Oocyte extrusion from the rest of the follicular structure is significantly decreased when small follicles are cultured in groups (Fig. 11). Our data suggest that this is due to higher numbers of TZPs in follicles grown in a group compared with follicles cultured individually. While oocyte extrusion is probably not a physiological phenotype, primarily due to the arrangement of follicles within the ovary and the structure of the ovary itself, the insufficient formation of TZPs within poorly growing small follicles may be. Several factors have been identified that regulate the formation of TZPs in growing follicles, including FSH and an oocyte-specific protein, GDF9 (Carabatsos et al. 1998, Combelles et al. 2004). Oocytes begin secreting GDF9 when the follicle enters the growing pool and deletion of GDF9 results in failure to progress through follicle development (Carabatsos et al. 2000). Based on the observations that oocytespecific factors regulate TZP formation and on classic studies that suggest that the oocyte orchestrates the rate of follicle development through regulation of granulosa cell function, it was logical to speculate that oocytes themselves could support the growth of individual follicles (Eppig et al. 1997, Eppig 2001, Gilchrist et al. 2001, 2006, Su et al. 2009). Our data, however, suggest that oocytes alone or OSFs are not sufficient to support early follicle growth in vitro.

In contrast to oocyte-specific factors, the growth and development of an individual follicle can be supported by a bead containing multiple follicles (Fig. 11). This demonstrates that the follicle as a unit is necessary to produce the secreted factors responsible for the supportive effects of multiple follicle culture. Although we cannot rule out a contribution from the oocyte, the somatic granulosa cells seem to be required. The LAX experiments suggest, however, that the granulosa cells alone are not sufficient to support the growth of other follicles. Thus, there may be signaling from both the oocyte and the follicle that enhances growth but requires both components in a feedback mechanism. A strength of the alginate hydrogel system is that follicle architecture is maintained, allowing for the physiological functioning of the follicle $(\mathrm{Xu}$ et al. 2006a, 2006b, West-Farrell et al. 2009). Using this culture system should allow significant progress in 
understanding the dialog between the oocyte and the granulosa cells.

This study, in addition to improving IVFG and providing insight into how small follicles may be interacting together during normal follicle development, also has implications for understanding age-related fertility decline. According to mainstream thinking in the field, the physiological ovarian reserve is fixed and nonrenewable (Woodruff 2008, Oatley \& Hunt 2012, Vogel 2012). As a female ages, there is a steady decline in both follicle number and quality. In our in vitro system, we observe that follicle quality - based on ability to survive, grow, and produce mature gametes - is diminished with decreasing follicle number, potentially mimicking what occurs during natural aging. Interestingly, we have previously demonstrated that follicles isolated from aging females and grown in vitro are significantly compromised compared with those isolated from younger counterparts (HirshfeldCytron et al. 2011). Thus, multiple follicle culture provides a tractable system to improve IVFG outcomes that may be related to age-related fertility decline. This culture system thus recapitulates the native environment of the follicle within the ovary by surrounding it with neighbors, furthering the movement toward recapitulating the ovary in vitro.

\section{Materials and Methods}

\section{Follicle isolation and encapsulation}

Ovaries were harvested from 12-day-old CD1 female mice. All animal experiments were approved by the Institutional Animal Use and Care Committee and were consistent with National Institutes of Health guidelines. A temperature-, humidity-, and light- (12 h light:12 h darkness) controlled barrier facility within Northwestern University's Center of Comparative Medicine was used to house and breed the mice. Mice were provided with food and water ad libitum. The mice were fed Teklad Global irradiated chow (2919 or 2916) that does not contain soybean or alfalfa meal and does contain minimal phytoestrogens. Follicles were mechanically isolated using insulin gauge needles in L15 media (Invitrogen) containing 1\% fetal bovine serum (FBS, Invitrogen). Individual follicles were maintained in minimal essential medium ( $\alpha M E M$ Glutamax, Invitrogen) containing $1 \% \mathrm{FBS}(\alpha \mathrm{MEM} / \mathrm{FBS})$ at $37{ }^{\circ} \mathrm{C}, 5 \% \mathrm{CO}_{2}$ in air for up to $2 \mathrm{~h}$ before encapsulation. Only follicles that were $85-115 \mu \mathrm{m}$ in diameter and displayed an intact morphology were selected for encapsulation and culture. Follicles were then encapsulated individually $(x 1)$ or in groups of five $(\mathrm{x} 5)$ or ten $(\mathrm{x} 10)$ in $0.5 \%(\mathrm{w} / \mathrm{v})$ alginate (NovaMatrix, Philadelphia, PA, USA) as described previously with the following modifications (Xu et al. 2006b, Supplementary Figure 1 , see section on supplementary data given at the end of this article). Follicles were placed in the center of a $5 \mu \mathrm{l}$ alginate drop made on a polypropylene mesh $(0.1 \mathrm{~mm}$ opening; McMaster-Carr, Atlanta, GA, USA). The mesh was immediately inverted and immersed in $50 \mathrm{mM} \mathrm{CaCl}_{2}$ and
$140 \mathrm{mM} \mathrm{NaCl}$ for $2 \mathrm{~min}$ to allow for cross-linking to occur. The alginate beads were carefully removed from mesh and placed in $\alpha \mathrm{MEM} / \mathrm{FBS}$ to recover for up to $2 \mathrm{~h}$. Alginate beads were placed in 96-well plates, with each well containing $100 \mu \mathrm{l}$ growth media (GM: aMEM Glutamax supplemented with $3 \mathrm{mg} / \mathrm{ml} \mathrm{BSA}, 10 \mathrm{mlU} / \mathrm{ml}$ recombinant FSH (A.F. Parlow, National Hormone and Pituitary Program, National Institute of Diabetes and Digestive and Kidney Diseases, USA), $1 \mathrm{mg} / \mathrm{ml}$ bovine fetuin, $5 \mu \mathrm{g} / \mathrm{ml}$ insulin, $5 \mu \mathrm{g} / \mathrm{ml}$ transferrin, and $5 \mathrm{ng} / \mathrm{ml}$ selenium (Sigma-Aldrich)). For all experiments, a single bead was placed in each well, except for the $x 1+x 10$ condition in which a bead with a single follicle was placed in the same well as a bead with ten follicles.

\section{Follicle culture, growth, and survival}

Follicles were cultured at $37^{\circ} \mathrm{C}$ in $5 \% \mathrm{CO}_{2}$ for up to 13 days. Half of the culture media was exchanged with fresh GM every other day. Follicles were imaged at the time of media changes with a Leica DM IRB inverted microscope using $4 \times, 10 \times$, or $20 \times$ objective (Leica Microsystems, Heidelberg, Germany). In the $x 5$ and $\times 10$ beads, individual follicles could be tracked by monitoring relative positions. Follicle growth curves were obtained by plotting the average follicle diameter measurements obtained from the images throughout culture. Follicle diameters were calculated by averaging two perpendicular measurements taken from basement membrane to basement membrane using ImageJ software (National Institutes of Health). Growth and survival data were reported until day 8 , by which time several follicles grown in the $x 5$ and $x 10$ conditions had fused making accurate measurements difficult. Follicle survival was classified morphologically. Follicles were considered dead if they had unhealthy appearing oocytes and/or granulosa cells or if the integrity between the oocyte and the somatic cells was irreversibly compromised.

\section{Immunocytochemistry}

Follicles were fixed in 3.8\% paraformaldehyde (Electron Microscopy Sciences, Hatfield, PA, USA) containing $0.1 \%$ Triton X-100 (Sigma-Aldrich) for $1 \mathrm{~h}$ at room temperature (RT). After fixation, follicles were blocked in PBS containing $0.3 \%$ BSA and $0.01 \%$ Tween 20 (blocking solution) and then incubated in anti-laminin B (1:50) (Sigma-Aldrich) for 16-18 h at $4{ }^{\circ} \mathrm{C}$. The primary antibody was detected using Alexa Fluor 488-conjugated Donkey anti-rabbit secondary antibody (Invitrogen) for $1 \mathrm{~h}$ at RT (1:100, Invitrogen). Simultaneous staining for F-actin was performed using Rhodamine- or Alexa Fluor 633-phalloidin (1:50, Invitrogen). Follicles were washed in blocking solution following antibody incubations and mounted in Vectashield containing DAPI to detect DNA (Vector Laboratories, Burlingame, CA, USA). Follicles were imaged with a Leica SP5 inverted laser-scanning confocal microscope with either a $40 \times$ or $63 \times$ objective (Leica Microsystems).

\section{TZP analysis}

Follicles encapsulated as $\mathrm{x} 1$ or $\mathrm{x} 10$ were cultured for 2 days and then removed from the alginate by incubating in $a$ 
$10 \mathrm{IU} / \mathrm{ml}$ solution of alginate lyase (Sigma-Aldrich) for $10 \mathrm{~min}$. For TZP imaging, follicles were fixed and stained for F-actin and DNA as described earlier, and a single confocal image was taken through the widest cross section of the oocyte. Line scan quantification and oocyte diameter measurements were performed as previously (Barrett et al. 2010). Briefly, using Leica analysis software, four-pixel lines, $10 \mu \mathrm{m}$ in length, were drawn throughout the zona pellucida around the oocyte in the image and an intensity profile was created for each line. The frequency of TZPs was determined by quantifying the number of peaks above the background threshold in the intensity profile. The background threshold was determined independently for each follicle by measuring the intensity at a region lacking staining for F-actin. Quantification of granulosa cells was done by counting the number of granulosa cell nuclei in the same cross section used for the line scan analysis.

\section{In vitro oocyte maturation}

In vitro maturation was performed after 9 or 13 days of culture, as described previously (Xu et al. 2006a, Shikanov et al. 2009). Briefly, follicles were removed from the alginate following a 10-min incubation in a $10 \mathrm{IU} / \mathrm{ml}$ solution of alginate lyase (Sigma-Aldrich) and transferred to in vitro maturation media (aMEM Glutamax containing $5 \mathrm{ng} / \mathrm{ml}$ epidermal growth factor, $0.2 \mathrm{IU} / \mathrm{ml} \mathrm{FSH}$ and $1.5 \mathrm{IU} / \mathrm{ml} \mathrm{hCG}$ ) for $14-16 \mathrm{~h}$ at $37^{\circ} \mathrm{C}$ in $5 \% \mathrm{CO}_{2}$ in air. Following in vitro maturation, cumulus cells were removed by treatment with $0.3 \%$ hyaluronidase and their morphology was assessed by light microscopy, as previously (Eppig \& O'Brien 1996). Oocytes that did not resume meiosis and instead remained arrested in prophase of meiosis I as evidenced by an intact GV were classified as GV-intact oocytes. Oocytes that resumed meiosis and reached metaphase of MII as evidenced by polar body extrusion were classified as MII-arrested oocytes. Those oocytes that resumed meiosis but did not reach MII, as evidenced by lack of both a GV and a polar body, were referred to as oocytes that had undergone GV breakdown. Finally, degenerate oocytes were also documented.

\section{Oocyte coculture and oocyte-secreted protein culture}

Immature oocytes from preantral follicles were collected from postnatal day 12 animals, as previously (Pan et al. 2005). Animals used were from the same litters as those used for the corresponding follicle isolation. Individual follicles encapsulated in $0.5 \%$ alginate (as above) were cultured in the presence of 75 immature oocytes in 96-well culture plates. Oocytes were removed and replaced every $24 \mathrm{~h}$ at the same time as a half media change was done. Follicles and oocytes were imaged daily. For oocyte-secreted protein (OSP) culture, individual follicles encapsulated in $0.5 \%$ alginate were cultured in GM as previously (Hussein et al. 2005) with the following modifications: $500 \mathrm{ng} / \mathrm{ml}$ GDF9 (R\&D Systems, Minneapolis, MN, USA), $500 \mathrm{ng} / \mathrm{ml}$ BMP15 (R\&D Systems), and 100 ng/ml FGF8 (R\&D Systems).

\section{LAX culture}

Oocytectomized follicles, or follicles without an oocyte, were produced by LAX. Follicles with a diameter of $\sim 100 \mathrm{~mm}$ were isolated from PND $12 \mathrm{CD} 1$ animals as above and held in aMEM/FBS at $37^{\circ} \mathrm{C}, 5 \% \mathrm{CO}_{2}$ in air for up to $2 \mathrm{~h}$ during oocytectomy, and before encapsulation. A standard microinjection setup equipped with a XYClone laser objective system (Hamilton-Thorne, Beverly, MA, USA) was used to laser ablate oocytes enclosed within small ovarian follicles. Follicles were placed on the microscope stage in a drop of L15 media (Invitrogen) containing 0.1\% PVP (Sigma-Aldrich) under mineral oil. The laser was focused on the GV of the oocyte and the oocyte was subjected to a $1 \mathrm{~s}$ laser pulse (100\% power, 200 pulses/s, $370 \mu$ s pulse width). Oocytes, which had a visibly damaged GV but intact granulosa cells, were designated LAX follicles. The specific damage to the oocyte was confirmed using Live/Dead Cell Viability assay (Invitrogen) $1 \mathrm{~h}$ post-laser treatment. Briefly, control follicles and LAX follicles were incubated in the presence of $1 \mu \mathrm{m}$ calcein $\mathrm{AM}$ and $2 \mu \mathrm{m}$ ethidium homodimer in $\alpha \mathrm{MEM} / \mathrm{FBS}$ at $37{ }^{\circ} \mathrm{C}, 5 \% \mathrm{CO}_{2}$ in air for $1 \mathrm{~h}$. Follicles were washed through media and imaged on a Nikon Ti Eclipse inverted microscope equipped with a fluorescent light source and the appropriate filters (Nikon Instruments, Inc., Melville, NY, USA). For culture, LAX follicles were encapsulated in groups of 10 and placed in a culture well with an individually encapsulated follicle, as for the $x 1+x 10$ cultures. The individual follicle was imaged to track growth and media was changed every other day.

\section{Statistical analysis}

Plotting of results and statistical analysis was done using GraphPad Prism (La Jolla, CA, USA). Growth data were analyzed using two-way ANOVA followed by Bonferroni posttest for single time point comparisons. A $P$ value of $<0.05$ was considered statistically significant. TZP quantification, oocyte diameter, and granulosa cell number data were each analyzed using an unpaired $t$-test. A $P$ value of $<0.05$ was considered significant.

\section{Supplementary data}

This is linked to the online version of the paper at http://dx.doi. org/10.1530/REP-12-0233.

\section{Declaration of interest}

The authors declare that there is no conflict of interest that could be perceived as prejudicing the impartiality of the research reported.

\section{Funding}

This work was supported by Award Number U54HD041857 from the Eunice Kennedy Shriver National Institute of Child Health and Human Development. The content is solely the responsibility of the authors and does not necessarily represent the official views of the National Institutes of Health. 


\section{Acknowledgements}

The authors thank Erin Jackson and Jennifer Pahnke for technical assistance.

\section{References}

Abir R, Franks S, Mobberley MA, Moore PA, Margara RA \& Winston RM 1997 Mechanical isolation and in vitro growth of preantral and small antral human follicles. Fertility and Sterility 68 682-688. (doi:10.1016/ S0015-0282(97)00264-1)

Abir R, Roizman P, Fisch B, Nitke S, Okon E, Orvieto R \& Ben Rafael Z 1999 Pilot study of isolated early human follicles cultured in collagen gels for 24 hours. Human Reproduction 14 1299-1301. (doi:10.1093/humrep/ 14.5.1299)

Abir R, Fisch B, Nitke S, Okon E, Raz A \& Ben Rafael Z 2001 Morphological study of fully and partially isolated early human follicles. Fertility and Sterility 75 141-146. (doi:10.1016/S0015-0282(00)01668-X)

Abir R, Nitke S, Ben-Haroush A \& Fisch B 2006 In vitro maturation of human primordial ovarian follicles: clinical significance, progress in mammals, and methods for growth evaluation. Histology and Histopathology 21 887-898.

Amorim CA, Van Langendonckt A, David A, Dolmans M-M \& Donnez J 2009 Survival of human pre-antral follicles after cryopreservation of ovarian tissue, follicular isolation and in vitro culture in a calcium alginate matrix. Human Reproduction 24 92-99. (doi:10.1093/humrep/ den343)

Anderson E \& Albertini DF 1976 Gap junctions between the oocyte and companion follicle cells in the mammalian ovary. Journal of Cell Biology 71 680-686. (doi:10.1083/jcb.71.2.680)

Barrett SL, Shea LD \& Woodruff TK 2010 Noninvasive index of cryorecovery and growth potential for human follicles in vitro. Biology of Reproduction 82 1180-1189. (doi:10.1095/biolreprod.109.082933)

Carabatsos MJ, Elvin J, Matzuk MM \& Albertini DF 1998 Characterization of oocyte and follicle development in growth differentiation factor9-deficient mice. Developmental Biology 204 373-384. (doi:10.1006/ dbio.1998.9087)

Carabatsos MJ, Sellitto C, Goodenough DA \& Albertini DF 2000 Oocyte-granulosa cell heterologous gap junctions are required for the coordination of nuclear and cytoplasmic meiotic competence. Developmental Biology 226 167-179. (doi:10.1006/dbio.2000.9863)

Combelles CMH, Carabatsos MJ, Kumar TR, Matzuk MM \& Albertini DF 2004 Hormonal control of somatic cell oocyte interactions during ovarian follicle development. Molecular Reproduction and Development 69 347-355. (doi:10.1002/mrd.20128)

Cortvrindt R, Smitz J \& Van Steirteghem AC 1996 In-vitro maturation, fertilization and embryo development of immature oocytes from early preantral follicles from prepuberal mice in a simplified culture system. Human Reproduction 11 2656-2666. (doi:10.1093/oxfordjournals. humrep.a019188)

Da Silva-Buttkus P, Marcelli G, Franks S, Stark J \& Hardy K 2009 Inferring biological mechanisms from spatial analysis: prediction of a local inhibitor in the ovary. PNAS 106 456-461. (doi:10.1073/pnas. 0810012106)

Dunning KR, Akison LK, Russell DL, Norman RJ \& Robker RL 2011 Increased $\beta$-oxidation and improved oocyte developmental competence in response to L-carnitine during ovarian in vitro follicle development in mice. Biology of Reproduction 85 548-555. (doi:10.1095/biolreprod. 110.090415)

Eppig JJ 2001 Oocyte control of ovarian follicular development and function in mammals. Reproduction 122 829-838. (doi:10.1530/rep.0. 1220829)

Eppig JJ \& O'Brien MJ 1996 Development in vitro of mouse oocytes from primordial follicles. Biology of Reproduction 54 197-207. (doi:10.1095/ biolreprod54.1.197)

Eppig JJ \& Schroeder AC 1989 Capacity of mouse oocytes from preantral follicles to undergo embryogenesis and development to live young after growth, maturation, and fertilization in vitro. Biology of Reproduction 41 268-276. (doi:10.1095/biolreprod41.2.268)
Eppig JJ, Wigglesworth K, Pendola F \& Hirao Y 1997 Murine oocytes suppress expression of luteinizing hormone receptor messenger ribonucleic acid by granulosa cells. Biology of Reproduction $\mathbf{5 6}$ 976-984. (doi:10.1095/biolreprod56.4.976)

Gilchrist RB, Ritter LJ \& Armstrong DT 2001 Mouse oocyte mitogenic activity is developmentally coordinated throughout folliculogenesis and meiotic maturation. Developmental Biology 240 289-298. (doi:10. 1006/dbio.2001.0451)

Gilchrist RB, Morrissey MP, Ritter LJ \& Armstrong DT 2003 Comparison of oocyte factors and transforming growth factor- $\beta$ in the regulation of DNA synthesis in bovine granulosa cells. Molecular and Cellular Endocrinology 201 87-95. (doi:10.1016/S0303-7207(02)00429-X)

Gilchrist RB, Ritter LJ \& Armstrong DT 2004 Oocyte-somatic cell interactions during follicle development in mammals. Animal Reproduction Science 82-83 431-446. (doi:10.1016/j.anireprosci.2004.05.017)

Gilchrist RB, Ritter LJ, Myllymaa S, Kaivo-oja N, Dragovic RA, Hickey TE, Ritvos O \& Mottershead DG 2006 Molecular basis of oocyte-paracrine signalling that promotes granulosa cell proliferation. Journal of Cell Science 119 3811-3821. (doi:10.1242/jcs.03105)

Gutierrez CG, Ralph JH, Telfer EE, Wilmut I \& Webb R 2000 Growth and antrum formation of bovine preantral follicles in long-term culture in vitro. Biology of Reproduction 62 1322-1328. (doi:10.1095/ biolreprod62.5.1322)

Hirshfeld-Cytron JE, Duncan FE, Xu M, Jozefik JK, Shea LD \& Woodruff TK 2011 Animal age, weight and estrus cycle stage impact the quality of in vitro grown follicles. Human Reproduction 26 2473-2485. (doi:10.1093/humrep/der183)

Hornick JE, Duncan FE, Shea LD \& Woodruff TK 2012 Isolated primate primordial follicles require a rigid physical environment to survive and grow in vitro. Human Reproduction 27 1801-1810. (doi:10.1093/ humrep/der468)

Hovatta O, Silye R, Abir R, Krausz T \& Winston RM 1997 Extracellular matrix improves survival of both stored and fresh human primordial and primary ovarian follicles in long-term culture. Human Reproduction 12 1032-1036. (doi:10.1093/humrep/12.5.1032)

Hovatta O, Wright C, Krausz T, Hardy K \& Winston RM 1999 Human primordial, primary and secondary ovarian follicles in long-term culture: effect of partial isolation. Human Reproduction 14 2519-2524. (doi:10.1093/humrep/14.10.2519)

Hussein TS, Froiland DA, Amato F, Thompson JG \& Gilchrist RB 2005 Oocytes prevent cumulus cell apoptosis by maintaining a morphogenic paracrine gradient of bone morphogenetic proteins. Journal of Cell Science 118 5257-5268. (doi:10.1242/jcs.02644)

Jeruss JS \& Woodruff TK 2009 Preservation of fertility in patients with cancer. New England Journal of Medicine 360 902-911. (doi:10.1056/ NEJMra0801454)

Jin SY, Lei L, Shikanov A, Shea LD \& Woodruff TK 2009 A novel two-step strategy for in vitro culture of early-stage ovarian follicles in the mouse. Fertility and Sterility 93 2633-2639. (doi:10.1016/j.fertnstert. 2009.10.027)

Kidder GM \& Mhawi AA 2002 Gap junctions and ovarian folliculogenesis. Reproduction 123 613-620. (doi:10.1530/rep.0.1230613)

Kreeger PK, Deck JW, Woodruff TK \& Shea LD 2006 The in vitro regulation of ovarian follicle development using alginate-extracellular matrix gels. Biomaterials 27 714-723. (doi:10.1016/j.biomaterials. 2005.06.016)

Newton H, Picton H \& Gosden RG 1999 In vitro growth of oocytegranulosa cell complexes isolated from cryopreserved ovine tissue. Journal of Reproduction and Fertility 115 141-150. (doi:10.1530/jrf.0. 1150141)

Oatley J \& Hunt PA 2012 Of mice and (wo)men: purified oogonial stem cells from mouse and human ovaries. Biology of Reproduction 86196. (doi:10.1095/biolreprod.112.100297)

O'brien MJ, Pendola JK \& Eppig JJ 2003 A revised protocol for in vitro development of mouse oocytes from primordial follicles dramatically improves their developmental competence. Biology of Reproduction 68 1682-1686. (doi:10.1095/biolreprod.102.013029)

Pan H, O'brien MJ, Wigglesworth K, Eppig JJ \& Schultz RM 2005 Transcript profiling during mouse oocyte development and the effect of gonadotropin priming and development in vitro. Developmental Biology 286 493-506. (doi:10.1016/j.ydbio.2005.08.023) 
Pedersen T \& Peters H 1968 Proposal for a classification of oocytes and follicles in the mouse ovary. Journal of Reproduction and Fertility 17 555-557. (doi:10.1530/jrf.0.0170555)

Peters H, Byskov AG, Himelstein-Braw R \& Faber M 1975 Follicular growth: the basic event in the mouse and human ovary. Journal of Reproduction and Fertility 45 559-566. (doi:10.1530/jrf.0.0450559)

Picton HM, Danfour MA, Harris SE, Chambers EL \& Huntriss J 2003 Growth and maturation of oocytes in vitro. Reproduction. Supplement 61 445-462.

Picton HM, Harris SE, Muruvi W \& Chambers EL 2008 The in vitro growth and maturation of follicles. Reproduction 136 703-715. (doi:10.1530/ REP-08-0290)

Romero S \& Smitz J 2010 Exposing cultured mouse ovarian follicles under increased gonadotropin tonus to aromatizable androgens influences the steroid balance and reduces oocyte meiotic capacity. Endocrine 38 243-253. (doi:10.1007/s12020-010-9380-y)

Roy SK \& Treacy BJ 1993 Isolation and long-term culture of human preantral follicles. Fertility and Sterility 59 783-790.

Schmidt KT, Larsen EC, Andersen CY \& Andersen AN 2010 Risk of ovarian failure and fertility preserving methods in girls and adolescents with a malignant disease. BJOG: an International Journal of Obstetrics and Gynaecology 117 163-174. (doi:10.1111/j.1471-0528.2009.02408.x)

Scott JE, Zhang P \& Hovatta O 2004 Benefits of 8-bromo-guanosine $3^{\prime}, 5^{\prime}$-cyclic monophosphate (8-br-cGMP) in human ovarian cortical tissue culture. Reproductive Biomedicine online 8 319-324. (doi:10.1016/ S1472-6483(10)60912-1)

Shikanov A, Xu M, Woodruff TK \& Shea LD 2009 Interpenetrating fibrinalginate matrices for in vitro ovarian follicle development. Biomaterials 30 5476-5485. (doi:10.1016/j.biomaterials.2009.06.054)

Smitz J, Dolmans MM, Donnez J, Fortune JE, Hovatta O, Jewgenow K, Picton HM, Plancha C, Shea LD, Stouffer RL et al. 2010 Current achievements and future research directions in ovarian tissue culture, in vitro follicle development and transplantation: implications for fertility preservation. Human Reproduction Update 16 395-414. (doi:10.1093/ humupd/dmp056)

Songsasen N, Woodruff TK \& Wildt DE 2011 In vitro growth and steroidogenesis of dog follicles are influenced by the physical and hormonal microenvironment. Reproduction 142 113-122. (doi:10.1530/ REP-10-0442)

Spears N, Boland NI, Murray AA \& Gosden RG 1994 Mouse oocytes derived from in vitro grown primary ovarian follicles are fertile. Human Reproduction 9 527-532.

Su YQ, Sugiura K \& Eppig JJ 2009 Mouse oocyte control of granulosa cell development and function: paracrine regulation of cumulus cell metabolism. Seminars in Reproductive Medicine 27 32-42. (doi:10. 1055/s-0028-1108008)

Sugiura K, Su Y-Q, Diaz FJ, Pangas SA, Sharma S, Wigglesworth K, O'brien MJ, Matzuk MM, Shimasaki S \& Eppig JJ 2007 Oocyte-derived BMP15 and FGFs cooperate to promote glycolysis in cumulus cells. Development 134 2593-2603. (doi:10.1242/dev.006882)

Tagler D, Tu T, Smith RM, Anderson NR, Tingen CM, Woodruff TK \& Shea LD 2012 Embryonic fibroblasts enable the culture of primary ovarian follicles within alginate hydrogels. Tissue Engineering Part A 18 1229-1238. (doi:10.1089/ten.tea.2011.0418)

Telfer EE, Binnie JP, McCaffery FH \& Campbell BK 2000 In vitro development of oocytes from porcine and bovine primary follicles. Molecular and Cellular Endocrinology 163 117-123. (doi:10.1016/ S0303-7207(00)00216-1)

Telfer EE, McLaughlin M, Ding C \& Thong KJ 2008 A two-step serum-free culture system supports development of human oocytes from primordial follicles in the presence of activin. Human Reproduction 23 1151-1158. (doi:10.1093/humrep/den070)

Thomas FH, Campbell BK, Armstrong DG \& Telfer EE 2007 Effects of IGF-I bioavailability on bovine preantral follicular development in vitro. Reproduction 133 1121-1128. (doi:10.1530/REP-06-0382)

Ting AY, Yeoman RR, Lawson MS \& Zelinski MB 2011 In vitro development of secondary follicles from cryopreserved rhesus macaque ovarian tissue after slow-rate freeze or vitrification. Human Reproduction 26 2461-2472. (doi:10.1093/humrep/der196)
Tingen CM, Kiesewetter SE, Jozefik J, Thomas C, Tagler D, Shea L \& Woodruff TK 2011 A macrophage and theca cell-enriched stromal cell population influences growth and survival of immature murine follicles in vitro. Reproduction 141 809-820. (doi:10.1530/REP-10-0483)

Vogel G 2012 Reproductive biology. Potential egg stem cells reignite debate. Science 335 1029-1030. (doi:10.1126/science.335.6072.1029)

Wandji SA, Srsen V, Voss AK, Eppig JJ \& Fortune JE 1996 Initiation in vitro of growth of bovine primordial follicles. Biology of Reproduction $\mathbf{5 5}$ 942-948. (doi:10.1095/biolreprod55.5.942)

Wandji SA, Srsen V, Nathanielsz PW, Eppig JJ \& Fortune JE 1997 Initiation of growth of baboon primordial follicles in vitro. Human Reproduction 12 1993-2001. (doi:10.1093/humrep/12.9.1993)

West-Farrell ER, Shea LD \& Woodruff TK 2007a Engineering the follicle microenvironment. Seminars in Reproductive Medicine 25 287-299. (doi:10.1055/s-2007-980222)

West-Farrell ER, Xu M, Woodruff TK \& Shea LD 2007b Physical properties of alginate hydrogels and their effects on in vitro follicle development. Biomaterials 28 4439-4448. (doi:10.1016/j.biomaterials.2007.07.001)

West-Farrell ER, Xu M, Gomberg MA, Chow YH, Woodruff TK \& Shea LD 2009 The mouse follicle microenvironment regulates antrum formation and steroid production: alterations in gene expression profiles. Biology of Reproduction 80 432-439. (doi:10.1095/biolreprod.108.071142)

Woodruff TK 2008 Making eggs: is it now or later? Nature Medicine 14 1190-1191. (doi:10.1038/nm1108-1190)

Woodruff TK \& Shea LD 2010 A new hypothesis regarding ovarian follicle development: ovarian rigidity as a regulator of selection and health. Journal of Assisted Reproduction and Genetics 28 3-6. (doi:10.1007/ s10815-010-9478-4)

Wright CS, Hovatta O, Margara R, Trew G, Winston RM, Franks S \& Hardy K 1999 Effects of follicle-stimulating hormone and serum substitution on the in-vitro growth of human ovarian follicles. Human Reproduction 14 1555-1562. (doi:10.1093/humrep/14.6.1555)

Wu J, Emery BR \& Carrell DT 2001 In vitro growth, maturation, fertilization, and embryonic development of oocytes from porcine preantral follicles. Biology of Reproduction 64 375-381. (doi:10.1095/biolreprod64.1.375)

Xu M, Kreeger PK, Shea LD \& Woodruff TK 2006a Tissue-engineered follicles produce live, fertile offspring. Tissue Engineering 12 2739-2746. (doi:10.1089/ten.2006.12.2739)

Xu M, West-Farrell ER, Shea LD \& Woodruff TK $2006 b$ Identification of a stage-specific permissive in vitro culture environment for follicle growth and oocyte development. Biology of Reproduction 75 916-923. (doi:10. 1095/biolreprod.106.054833)

Xu M, Barrett SL, West-Farrell ER, Kondapalli LA, Kiesewetter SE, Shea LD \& Woodruff TK 2009a In vitro grown human ovarian follicles from cancer patients support oocyte growth. Human Reproduction 24 2531-2540. (doi:10.1093/humrep/dep228)

Xu M, West-Farrell ER, Stouffer RL, Shea LD, Woodruff TK \& Zelinski MB $2009 b$ Encapsulated three-dimensional culture supports development of nonhuman primate secondary follicles. Biology of Reproduction $\mathbf{8 1}$ 587-594. (doi:10.1095/biolreprod.108.074732)

Xu J, Bernuci MP, Lawson MS, Yeoman RR, Fisher TE, Zelinski MB \& Stouffer RL 2010 Survival, growth, and maturation of secondary follicles from prepubertal, young, and older adult rhesus monkeys during encapsulated three-dimensional culture: effects of gonadotropins and insulin. Reproduction 140 685-697. (doi:10.1530/REP-10-0284)

Xu J, Lawson MS, Yeoman RR, Pau KY, Barrett SL, Zelinski MB \& Stouffer RL 2011 Secondary follicle growth and oocyte maturation during encapsulated three-dimensional culture in rhesus monkeys: effects of gonadotrophins, oxygen and fetuin. Human Reproduction 26 1061-1072. (doi:10.1093/humrep/der049)

Received 18 June 2012

First decision 23 July 2012

Revised manuscript received 13 September 2012

Accepted 23 October 2012 